\title{
TRAVESSIAS DO SUJEITO NO ENCONTRO COM A TECNOLOGIA, A ARTE E O MEIO ${ }^{1}$
}

Gisele Gonçalves Melles de Oliveira ${ }^{1}$, Joana Sanches-Justo ${ }^{2}$, Luli Hata $^{3}$

${ }^{1}$ Curso de Psicologia da UNIP - Assis - SP. ${ }^{2}$ Curso de Artes Visuais e Psicologia - UNOESTE. ${ }^{3}$ Curso de Artes Visuais UNOESTE. E-mail: gimelles@terra.com.br

\section{RESUMO}

$\mathrm{O}$ artigo trata do encontro entre a arte e suas tecnologias como experimentações do pensamento, que pode também representar um tempo, os modos de vida e os processos de subjetivação de uma sociedade. Para desenvolver este assunto, primeiramente contextualizou-se o panorama contemporâneo, no qual as novas conexões na sociedade em rede penetram de maneira única na esfera cultural e subjetiva. Em seguida são colcoadas considerações a respeito da relação entre a arte e a tecnologia, analisando a obra de Andréia Oliveira, CoRPosAsSoclaDos. Ao final, tece-se uma reflexão sobre a arte como possibilidade de resistência, experimentação e reinvenção na sociedade da informação.

Palavras-chave: arte, sociedade contemporânea, subjetivação, travessias, tecnologia.

\section{INTRODUÇÃO E OBJETIVOS}

A vida contemporânea é marcada pelo contato com as novas tecnologias, pela fluidez da informação e das relações, ambas pautadas na velocidade dos encontros e no pragmatismo do olhar. A tecnologia transformou a relação do homem com o tempo e o espaço: o tempo ganhou novas dimensões e as distâncias se encolheram, permitindo que os lugares e as pessoas sejam facilmente alcançados. Instaura-se, dessa maneira, uma nova forma de relacionamento com o outro, mediado pela virtualização, prescindindo o contato físico. Nesta configuração, o importante não é a relação ser real, mas apenas parecer. Trata-se de um jogo de aparências atestado por números: de amigos, de seguidores, de contatos, de "curtidas". A veiculação de aparências dentro das relações em rede levam o homem a um esvaziamento afetivo, uma vez que os vínculos perdem força pelo caráter passageiro e instável. Através de jogos, de interesses em comum evidenciados pelo "curtir" no facebook, da retransmissão de tweets, do compartilhamento de notícias e fofocas pela rede, a instabilidade promovida pela virtualização das relações se torna menos assustadora, mas não menos superficial, já que o homem vai consumindo passivamente o que lhe falta, aparentemente, em sua "existência real".

\footnotetext{
${ }^{1}$ O presente artigo parte da tese de doutorado A arte como resistência na sociedade da informação (2013), de Gisele Gonçalves Melles de Oliveira. Originalmente, foram analisadas as obras de Andréia Oliveira, aqui apresentada, e Michael Snow, Authorization, detalhada na introdução do livro de Philippe Dubois (v. referências), à luz das concepções de Deleuze e Guattari.
} 
Além disso, verifica-se que não existe espaço para vivenciar a angústia e o caos quando tudo que existe pode ser transformado em mercadoria, inclusive a felicidade. Transmite-se a ideia de que, hoje, só é infeliz quem quer, já que existem inúmeros produtos no mercado que garantem "alívio imediato da dor".

A partir desse panorama, é possível notar que é a própria subjetividade que está posta em questão: os modos de pensar, de agir, de sentir, independente do ambiente em que se inserem os sujeitos. Afinal, tratam-se de corpos que se compõem engendrados por tessituras temporalizadas, por tecnologias diversas, distintos da essencialidade do paradigma a-histórico, universalizante e naturalizado do homem. Neste sentido, rompe-se com o pensamento tradicional que supõe o ser individuado acabado, pois, imersos no mundo, os corpos revelam as marcas de seu modo de produção. Em um tempo onde tudo é simultâneo, abrem-se possibilidades de avançar em nossas travessias, principalmente no que diz respeito à imagem digital, como espaço de criação de mundo, como sensibilidade em relação ao tempo, aos desejos de trânsito atuais, afinal, como sugere Fonseca (2007), "se toda imagem é linguagem, temos então na imagem digital, um acesso ao ritmo e à estética da produção da subjetividade contemporânea" (FONSECA, 2007, p.333).

A arte se constitui como meio de singularização da subjetividade, representando as relações estabelecidas pelos sujeitos da história humana e, atualmente, mantém uma intrínseca relação com as tecnologias. Valendo-se da linguagem própria do mundo atual e dos meios de veiculação de suas mensagens, a arte contemporânea expressa a realidade cultural e subjetiva em que se vive. Entretanto, mal recebida e mal interpretada pela opinião pública em geral, ela tem sido, na maior parte das vezes, relegada a ocupar um lugar restrito, para um público especializado. Observa-se uma situação diversa das motivações de artistas da década de 1960, quando utilizavam objetos do cotidiano em suas obras, estabelecendo uma conexão com a vida comum das pessoas. Por exemplo, o grupo Fluxus, movimento internacional de artistas, cineastas, músicos e escritores, do qual fez parte Yoko Ono, era liderado por George Maciunas, cujo manifesto, na esteira de Duchamp, questionava a exclusividade da arte instituída, isto é, a que se contempla em galerias e museus, e propunha a participação dos espectadores na produção da obra, aproximando a arte das pessoas em "um vínculo essencial entre objetos cotidianos, eventos e arte" (RUSH, 2006, p. 18).

A artista Mieko Shiomi, em um desses eventos, convidou o público a abrir algo fechado. Ao final, pediu que os participantes escrevessem o que havia acontecido. Segundo Rush (2006, p. 18), 
"esta simples tarefa tornou-se um manifesto contra a arrogância da arte em museus, bem como uma ação participativa porque as pessoas se reuniram para realizá-la".

Atualmente, a arte é produzida em um cenário em que nada existe para durar, para permanecer. A tecnologia está em constante transformação, assim como o homem. A fluidez com a qual vive o homem contemporâneo dá margem à emergência de uma crise de identidade que se constitui na perda de raízes, na substituição das certezas, do concreto, pelo fluido e passageiro. Nesse sentido, o homem contemporâneo vive a angústia da fragmentação, da ruptura com a concretude e com a estabilidade, o desfacelamento dos laços e vínculos que, assim como a identidade, agora se configuram no ambiente virtual, permeados pela constante fluidez e transformação. Essas questões influenciam a arte, sendo absorvidas na própria estruturação das obras, tornando-as singulares em relação às obras de épocas culturais precedentes.

De fato, a intensificação da experiência de ruptura, que ocorre para além do plano da consciência e que desemboca nos próprios modos do processo de subjetivação, é parte constituinte do homem contemporâneo. Esses processos são inteiramente variáveis, de acordo com as épocas, já que os saberes e poderes de cada período, a todo o momento, não param de ser recuperados e de, também, serem submetidos a relações de força. Nas palavras de Deleuze:

Um processo de subjetivação, isto é, uma produção de modo de existência, não pode se confundir com o sujeito, a menos que se destitua de toda interioridade e mesmo de toda identidade. A subjetivação sequer tem a ver com a 'pessoa': é uma individuação, particular ou coletiva, que caracteriza um acontecimento (uma hora do dia, um rio, um vento, uma vida...). É um modo intensivo e não um sujeito pessoal. É uma dimensão específica, sem a qual não se poderia ultrapassar o saber nem resistir ao poder (DELEUZE, 1992, p. 124).

Ao experimentar a ruptura, a mudança, este homem se transfigura, ao mesmo tempo em que esta experiência o afeta. O que está em jogo, nesta travessia de transformação, é a relação do homem com o caos. Assim como a infelicidade, ao homem não é permitido vivenciar o caos e as possibilidades dele decorrentes. Mais do que um estado de fragmentação e ruptura do eu, o caos pode ser considerado em sua positividade como processualidade que é própria a todos os corpos, como efeito de seu irresistível encontro com outros corpos, em oposição à identidade: caos como efeito da alteridade.

A identidade tomada como estrutura rígida que alicerça o homem se torna fluida e instável ao se deparar com a transitoriedade do caos. Este contato, por sua vez, propicia o encontro com o externo, o diferente, enfim, com o outro. Como uma revolução irreversível e contínua, o caos 
segue produzindo uma complexificação e diferenciação cada vez mais amplas. O caos, ao deixar de ser experimentado como recusa da ordem, como derradeiro, regressa menos terrível e possibilita um novo modo de subjetivação, em oposição à indissociável idealização de uma completude, de uma identidade. Neste contexto, origina-se um novo modo de subjetivação, particularmente processual, formada na abertura para o caos, para o outro.

Para a realização desta travessia, de experimentação da ruptura, o homem contemporâneo passa necessariamente por situações de tensão, afinal: "libertar a subjetividade da tutela do terror em relação ao outro e ao caos, passa, necessariamente, pela conquista da possibilidade de experimentá-los" (ROLNIK, 2002, p. 14). Na travessia para o caos, para o outro, ocorre um embate entre forças opostas, em nós e em nosso entorno, que se estabelecem como forças a favor, permitindo a abertura para novas configurações e que, inclusive, atuam como controle, como aponta Gilles Deleuze (1999).

Na reinvenção da relação entre a arte e a tecnologia, em que a hibridização de arte, ciências, mídias e pensamento produz novos paradoxos e questões, é possível observar essa travessia, ponto central de análise do presente estudo. A referida relação não é nova, mas é problematizada no contexto atual, em que a arte encontra, nas tecnologias emergentes, um campo de experimentação. Afinal, em cada sociedade, como sugere Deleuze (1992), as máquinas enunciam as formas sociais que lhe são capazes de dar origem e de utilizá-las.

\section{METODOLOGIA}

Este estudo teve caráter bibliográfico, resgatando autores consagrados na discussão do panorama contemporâneo da sociedade, bem como autores que abordam a primazia da imagem e a sociedade capitalista de acumulação flexível. Deleuze e Guattari forneceram o fundamento teórico para a discussão do tema proposto.

\section{RESULTADOS}

No processo de produção da obra de arte CoRPosAsSoclaDos ${ }^{2}$, Andréia Oliveira (2010) dá visibilidade para as travessias que a paisagem contemporânea possibilita. A associação entre corpos proposta inicia-se com a xilogravura: o corpo da modelo é transposto para a madeira, impresso, digitalizado, editado e animado no computador. Por fim, elas são lançadas em um programa no qual somam-se sons capturados do interior do corpo humano. Então, entre tantas

2 Instalação que faz parte de projeto de doutorado da artista, defendida em 2010 (v. referências). Imagens disponíveis em http://www.inflexions.org/n4_t_oliveira.html. 
travessias, projetam-se e amplificam-se imagens e sons na videoinstalação interativa. Nela, o espectador é convidado a compartilhar o mesmo meio das figuras femininas que são projetadas nas paredes e convidado à experiência estética. Seu corpo é contagiado ao experimentar a obra, em travessias:

Quando se adentra na exposição CoRPosAsSoclaDos, propõe-se um encontro distraído com os corpos presentes. Os corpos femininos na parede vão se misturando entre si e com seus fundos, suas texturas. Surgem corpos (in) formes. Há um certo prazer nesses corpos quando a mão toca partes inusitadas e até age com outras funções: mão-cabeça, mão-vagina, mão-seio, mão-rosto... percorrem por instantes o corpo sem órgãos (OLIVEIRA, 2010, p. 51).

Em um corpo sem órgãos, somente as intensidades circulam e fazem a travessia. Ele não é espaço, não está no espaço, é a matéria não estratificada, na qual nada há para interpretar. 0 corpo sem órgãos, na definição de Deleuze e Guattari (1996), é o campo de imanência do desejo, onde este se define, sem qualquer referência exterior, como processo de produção. A experiência do corpo sem órgãos que a arte proporciona questiona a superfície do organismo, aqui compreendido como inimigo do corpo. Na definição de Deleuze e Guattari o organismo não é o corpo,

mas um estrato sobre o $\mathrm{CsO}$, quer dizer, um fenômeno de acumulação, de coagulação, de sedimentação que Ihe impõe formas, funções, ligações, organizações dominantes e hierarquizadas, transcendências organizadas para extrair um trabalho útil". A experimentação do corpo sem órgãos opõe-se aos organismos totalitários e fascistas, "o corpo sem órgãos nunca é o seu, o meu... É sempre um corpo (DELEUZE; GUATTARI, 1996, p. 28).

Trata-se de uma involução criativa que se dá sempre contemporânea. No encontro do corpo com a obra de arte, no intermezzo, na experimentação da travessia, percebe-se a possibilidade de desfazer gradativamente o organismo, "abrir o corpo a conexões que supõe todo um agenciamento, circuitos, conjunções, superposições e limiares, passagens e distribuições de intensidade, territórios e desterritorializações medidas à maneira de um agrimensor" (DELEUZE; GUATTARI, 1996, p. 28).

No "entre" dos corpos, na travessia, nota-se que eles não se findam em seus contornos, que não se trata de um corpo como unidade fechada, conectada a outro corpo também constituído como unidade: são travessias de multiplicidades de um corpo, que se conecta com as multiplicidades do outro corpo. Em outros termos, trata-se de assumir a multifacetação do próprio processo de subjetivação e das mesmas multifacetação e plurissignifação do outro. Ou de representá-las por meio 
de linguagens múltiplas, que atravessam a concretude das relações e transitam, virtualmente, por outros caminhos.

As tecnologias digitais, que compõem a atual rede social, assim como a obra de arte CoRPosAsSoclaDos, apresentam o potencial de abertura para as multiplicidades e as diferenciações do "fora", o que pode nos levar a perceber que também somos habitados pela multiplicidade exterior. A potencialização das velocidades, que a virtualização supõe, sugere-nos a produção de tempos e espaços mutantes, indicando-nos que a tecnologia digital, virtual, aproxima-se do pensamento filosófico, deslocando o sentido de totalização e unidade para o de multiplicidade e diferença. Para se considerarem as tecnologias digitais não só como ferramentas,

[...] faz-se preciso sair de generalidades e de dicotomias como homem/máquina, analógico/digital e penetrar nas singularidades em nível molecular, nas constituições e composições dos elementos, em suas tecnicidades que ocorrem nas relações de composição (OLIVEIRA, 2010, p. 189).

Em CoRPosAsSoclaDos, não identificamos apenas objetos físicos, mas as travessias, as conexões, as misturas, os híbridos, que compõem e variam a todo tempo. Nas palavras de Deleuze e Guattari (1992, p. 67), "pode-se, deve-se então supor uma multiplicidade de planos, já que nenhum deles abraçaria todo o caos sem nele recair, e que todos retêm apenas movimentos que se deixam dobrar juntos". Nessa obra, configuram-se travessias entre corpos, entre os elementos visuais e entre ambos, como movimento: arte-travessia, como receptora da vida, experiência do pensamento, do corpo pensante e do encontro com o caos.

A arte como experiência do pensamento se dá no encontro com as potências desconhecidas de um fora, sem a tentação de projetar um modelo ou paradigma, que possa servir de auxílio. No encontro com o caos, instaura-se o pensamento em que as misturas operam no corpo, abrem-se possibilidades, novos modos de experimentação e novos modos de existência. Nas travessias que a arte possibilita, passamos "da endo-sensação à exo-sensação" (DELEUZE; GUATTARI, 1992, p. 239). Para além dos compostos melódicos que constituem a natureza, a obra de arte, como composto estético, com os monumentos erguidos pelas sensações, abre um plano de composição sinfônica infinito, que sugere a abertura da casa ao universo. Não se trata apenas da função de isolar e juntar, mas da abertura para forças cósmicas, que tornam sensíveis seus efeitos sobre o habitante. Em sutis transições, ora as forças se fundem, ora se enfrentam, ora se alternam, ora "lançam um apelo misterioso que arranca o habitante do território, e o precipita numa viagem irresistível” (DELEUZE; GUATTARI, 1992, p. 240), como as lagostas que se lançam em 
uma grande peregrinação no fundo do mar. Sempre, dizem Deleuze e Guattari (1992), tanto a natureza como a arte conjugam, de infinitas maneiras, a Casa e o Universo, esses dois elementos vivos, os compostos melódicos finitos e o grande plano de composição infinito.

\section{DISCUSSÃO}

A relação entre a arte e a tecnologia é indissociável do recente quadro midiático, científico e cultural, que passa pelos mais diferentes saberes e processos: a travessia do analógico para o digital que presenciamos na fotografia, no cinema, e no vídeo; a informática e as possibilidades de conexões das redes; as neurociências, a cibernética, a valorização das ciências do vivo, em que o modelo biológico se cruza com o maquínico, com o digital, com as redes. Novos dispositivos tecnológicos estão criando novos circuitos para a arte: novos circuitos de travessias.

A paisagem contemporânea constitui-se como um vasto lugar de travessia, que se dá entre todas as formas artísticas e a cidade que habitamos: repletas de imagens, de movimento e velocidade, que nos introduzem em outras dimensões de tempo e de espaço, conduzindo-nos à experimentação do intermezzo, do entre-lugar. "As passagens são a arquitetura da cidade das imagens" (PEIXOTO, 2011, p. 237).

A velocidade instaurada, que caracteriza a paisagem atual, leva-nos a experimentar o meio, o entre as coisas, as multiplicidades do "entre". Não há mais fronteiras entre as linguagens e o suporte. Somente travessia.

Observamos, nos agenciamentos com as novas tecnologias, na leitura da obra CoRPosAsSoclaDos, que tramamos uma geometria dos acasos, onde encontramos, no labirinto virtual, uma metáfora do próprio pensamento, em contraponto às amplas rodovias da segurança e da razão. A experimentação da obra sugere que habitamos as travessias e estas chamam a atenção aos próprios modos de andar, aos percursos que indicam os caminhos, dos quais o sujeito contemporâneo, habitante do tempo, dispõe para entrar em contato com a infelicidade e a potencialidade criativa do caos. Assim, percebe-se a arte aliada da vida, desdobrando-se como possibilidade de experimentação e reinvenção para os habitantes da sociedade da informação, como possibilidade de resistência e de abertura a outros tempos e espaços e como possibilidade da reinvenção do olhar ou de exercitar um olhar estrangeiro: "olhar as coisas como se fosse a primeira vez, [...] livrar a paisagem da representação que se faz dela" (PEIXOTO, 1988, p. 363). 


\section{CONCLUSÃO}

Hoje, pela via da inserção no cotidiano, assumindo o caráter precário e fugaz das mensagens atuais, aparecendo em meio a uma profusão de dados informativos e comunicacionais, a obra de arte, sintonizada com os nossos dias, não faz mais do que expressar o clima cultural de nosso tempo. De fato, virtual, tecnológica, projeto, a arte contemporânea apresenta-se (embora isso não seja muito claro para nós, que vivemos este tempo), como uma das poucas possibilidades de denúncia e resistência aos cerceamentos impingidos aos processos de subjetivação pelos recursos de dominação de nosso tempo.

A arte nos permite fazer a travessia para além das sobreposições de imagens que configuram a sociedade da informação. Encontramos, na experiência com a arte, a possibilidade de linhas de fuga: a resistência. Afinal, não acreditamos que o objeto artístico, que se apresenta hoje como complexidade, seja apenas transgressor ou neutro, ou mesmo um composto estético, já que também está sujeito às capturas institucionais, ainda que, sendo realmente um objeto artístico, ele consiga, mesmo utilizando os próprios materiais institucionalizados, denunciar a manipulação a que somos submetidos.

\section{REFERÊNCIAS BIBLIOGRÁFICAS}

BAUMAN, Z. A Arte da Vida. Rio de Janeiro: Editora Zahar, 2009.

BRUM, E. Permissão para ser INfeliz. Revista época, São Paulo, 14 jan. 2013. Disponível em: http://revistaepoca.globo.com/Sociedade/eliane-brum/noticia/ 2013 /01/permissao-para-serinfeliz.html. Acesso em 23 abril 2013.

CASTELLS, M. A sociedade em rede. 7. ed. São Paulo: Paz e Terra, 2003.

DELEUZE, G. A imanência, uma vida... In: Terceira Margem, Rio de Janeiro, Ano IX, n. 11, p. 160164, 2004. Disponível em: <http://www.letras.ufrj.br/ciencialit/ terceiramargemonline/numero11/xiii.html>. Acesso em: 20 abr. 2012.

. Conversações. Rio de Janeiro: Editora 34, 1992.

DELEUZE, G.; GUATTARI, F. Mil Platôs: capitalismo e esquizofrenia. São Paulo: Editora 34, 1996. v. 3.

. Mil Platôs: capitalismo e esquizofrenia. São Paulo: Editora 34, 1997. v. 5.

DUBOIS, P. 0 ato fotográfico. Campinas: Papirus, 1994. 
FONSECA, T. M. G. O invisível da escritura: escavando a assinatura nua. In: LINS, D. (Org.). Nietzsche/Deleuze: arte, resistência: Simpósio Internacional de Filosofia. Rio de Janeiro: Forense Universitária, 2007, p. 321-339.

HALL, S. A identidade cultural na pós-modernidade. Rio de Janeiro: DP\&A, 2006.

LINS, D. Deleuze: o surfista da imanência. In: LINS, D.; GIL, J. Nietzsche/Deleuze: jogo e música. Rio de Janeiro: Forense Universitária, 2008.

ROLNIK, S. Apresentação. In: FIGUEIREDO, L. C. M. A invenção do psicológico: quatro séculos de subjetivação (1500-1900). 5. ed. São Paulo: Educ; Escuta, 2002. p. 13-17.

. Ninguém é Deleuziano. [nov., 1995]. Entrevistadores: L. Neto e S. Gadelha. O Povo, Fortaleza, Caderno Sábado, 18 nov. 1995. p. 6.

RUSH, M. Novas mídias na arte contemporânea. São Paulo: Martins Fontes, 2006.

SILVA, R. B.;SANCHES-JUSTO, J. Notas sobre "A Arte da Vida" de Zygmunt Bauman. Revista Espaço Acadêmico (UEM), Maringá, v. 11, n. 125, p.10-16, out. 2011.

OLIVEIRA, A. M. Corpos associados: interatividade e tecnicidade nas paisagens da arte. 2010. 213 f. Tese (Doutorado em Informática na Educação) - Centro Interdisciplinar de Novas Tecnologias na Educação, UFRS, Porto Alegre, 2010.

. Corpos associados. Disponível em: <http://www.inflexions.org/n4_t_oliveira.html>. Acesso em: 25 nov. 2012.

PEIXOTO, N. B. O olhar do estrangeiro. In: NOVAES, A. (Org.). O Olhar. São Paulo: Companhia das Letras, 1988. p. 361-366.

VIRILIO, P. Velocidade e política. São Paulo: Estação Liberdade, 1996. 